\title{
Clinical Features of
}

\section{Facioscapulohumeral Muscular Dystrophy (FSHD)}

A 90-year-old woman has always looked younger than her age. For the past few years, she has had trouble wearing her purse on her shoulder, and now wears a cross-body bag. She has trouble keeping her bra straps on her shoulders. She has a transverse smile, no forehead wrinkles, and mild forward sloping of her shoulders. Serum CK was normal. Genetic testing revealed a deletion on chromosome 4q35 [1], consistent with FSHD. Early involvement of the facial muscles results in a distinctive clinical presentation and may contribute to reduced facial wrinkles. Facioscapulohumeral muscular dystrophy (FSHD) is the third most common muscular dystrophy [2]. With widespread availability of genetic testing and clinical trials, a firm understanding of the typical clinical features [3] and muscle involvement in individuals with FSHD is necessary to ensure accurate and early diagnosis (Figure 1).

FSHD inheritance is autosomal dominant [4], with a high frequency of de novo cases [5]. Clinical involvement in FSHD is wide ranging, and severity of involvement is markedly variable, even within the same family [6]. Clinical variability can range from asymptomatic individuals with minimal clinical features to patients who have complete loss of ambulation due to weakness [7]. Age of on onset is variable. Symptoms often become clinically evident in the second decade, but many remain asymptomatic into late adulthood [8].

The classical FSHD presentation is asymmetric sequential face and shoulder-girdle weakness, followed by lower extremity, truncal and lower abdominal muscle weakness $[9,10]$. The restricted pattern of weakness can evolve over years or decades. The descending gradient of involvement is temporal, and does not necessarily reflect the degree of weakness of affected muscles. Facial weakness is often the earliest evident clinical feature. Affected individuals have reduced facial expression, and inability to drink from a straw or whistle. Patients with longstanding FSHD and facial muscle involvement typically demonstrate reduced facial wrinkling [11]. Symptoms progress to involve scapular and shoulder-girdle muscles frequently resulting in scapular winging. As a result of progressive shouldergirdle weaknesspatients losethe ability to elevate their arms or reach above shoulder level. Upper extremity weakness is the most common clinical symptom prompting initial evaluation [7]. Progressive shoulder and upper extremity atrophy and weakness ensue. Clinically, patients develop a forward sloping of their shoulders. Patients have difficulty wearing shoulder bags, and often need to wear either a backpack on both shoulders or wear a cross-body bag. Many affected woman have similar difficulties wearing bra straps or tank tops. Later on, elbow flexors become involved, affecting patient's ability to carry heavy items. Deltoid muscles are typically spared, especially in the early phase of the disease, and can remain strong despite involvement of biceps and triceps muscles. During the progressive course of the disease foot dorsiflexorsare affected. Patients frequently develop foot drop, and suffer from frequent falls. Orthotics and specialized

\section{Journal of Neurology and Psychology}

\section{Beth Stein ${ }^{1 *}$ and Alfred J. Spiro ${ }^{2}$}

${ }^{1}$ Department of Neurology, Albert Einstein College of Medicine, Montefiore Medical Center 111 East 210th Street, Bronx, NY 10461, USA

${ }^{2}$ Department of Neurology and Pediatrics, Albert Einstein College of Medicine, 1300 Morris Park Ave, Block room 330, Bronx, NY 10461, USA

\section{*Address for Correspondence}

Beth Stein, MD, Assistant Professor, Department of Neurology, Albert Einstein College of Medicine, Montefiore Medical Center 111 East 210th Street, Bronx, NY 10461, USA, E-mail: steinb@sjhmc.org

Copyright: (C) 2013 Stein B, et al. This is an open access article distributed under the Creative Commons Attribution License, which permits unrestricted use, distribution, and reproduction in any medium, provided the original work is properly cited.

Submission: 30 July 2013

Accepted: 22 October 2013

Published: 25 October 2013

Reviewed \& Approved by: Dr. Ghazala Hayat

Department of Neurology \& Psychiatry

Saint Louis University, USA

ankle-foot-orthoses are utilized to maintain ambulation, and prevent falls. Truncal muscles weakness develops as the disease progresses, and can be easily missed on muscle examination. Abdominal muscle involvement can result in a protuberant abdomen and lead to an increase in lumbar lordosis. Lower abdominal muscles are characteristically weaker than upper abdominal muscles, leading to a strikingly positive Beevor's sign $[10,12]$. In the later stages of the disease hip muscles and other proximal muscles can become involved. Patients with more severe disease can lose ambulation completely, necessitating the use of a wheelchair for mobility [7]. Due to the involvement of pelvic-girdle and other proximal muscles, advanced cases of FSHD may be difficult to distinguish from other limb-girdle muscular dystrophies [7].

Bulbar, extraocular muscles and cardiac muscles are relatively spared in FSHD. While rare, 5\% of FSHD patients develop atrial arrhythmias [5]. Retinal telangiectasias are seen in $60 \%$ of affected

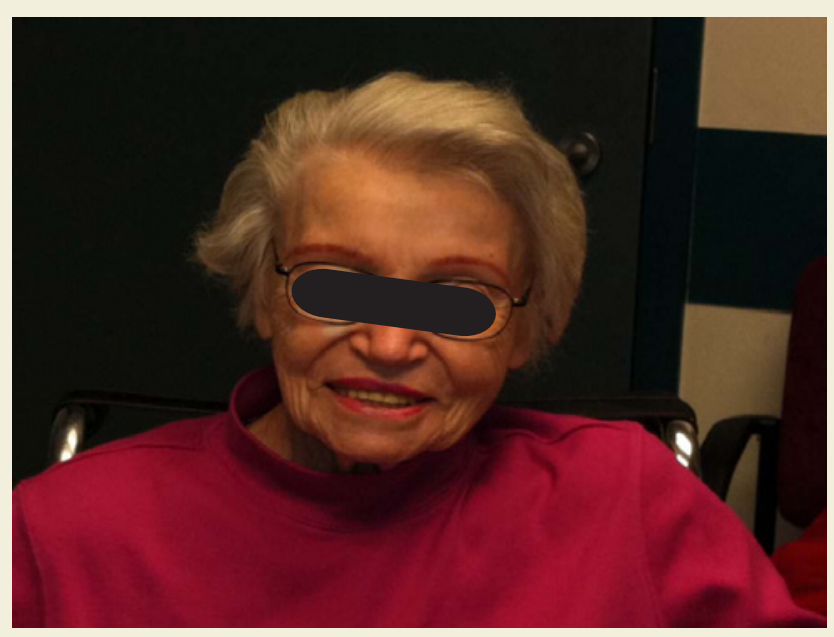

Figure 1: Reduced facial wrinkling in a woman diagnosed with FSHD at the age of 82 . 
individuals, and can rarely lead to retinal exudation and retinal detachment (Coat's syndrome) $[9,13]$. High frequency hearing loss is common and can be seen in approximately $75 \%$ of affected patients [13]. $1 \%$ of patients develops restrictive respiratory disease and requires ventilation. Respiratory muscle involvement is usually seen in patients with severe muscle weakness and advanced disease [14].

Prognosis in FSHD is variable, and is usually inversely related to age at onset of symptoms. The rate of progression is often slow and steady [15]. Patients typically report a stepwise progression of symptoms, where they experience a rapid deterioration of one muscle group, followed by long periods of stability [15]. This pattern of progression is repeated as the disease evolves. Life expectancy is generally not compromised by FSHD because cardiac and respiratory involvement is rare. $20 \%$ of affected individuals are wheelchairbound due to the disease. The remaining $80 \%$ have varying degrees of disability. There is a sub-population of patients with early onset FSHD, or infantile onset-FSHD who are severely disabled at an early age. Women tend to be less severely affected than men with FSHD [16]. There is a rough correlation between clinical disease severity and the size of gene deletion.

The clinical spectrum of FSHD is wide ranging, but often follows a slowly progressive course affecting arestricted groups of muscles. Identification of subtle clinical examination features specific to FSHD early in the disease course may lead to improved diagnosis of this common muscular dystrophy [17].

\section{References}

1. Tawil R, Grigg RRC (1997) Facioscapulohumeral muscular dystrophy. In: Rosenberg RN, Prusner SB, Di Mauro S, Barchi RI (Eds). The molecular and genetic basis of neurological disease. Boston: Butterworth Heinemann, pp. 931-938.

2. Padberg GW (2004) Facioscapulohumeral muscular dystrophy: a clinician's experience. In: Upadhaya M, Cooper DN (Eds). Facioscapulohumera muscular dystrophy: clinical medicine and molecular cell biology. Abingdon, UK: Garland Science/BIOS Scientific, pp. 41-54.

3. Padberg GW, Lunt PW, Koch M, Fardeau M (1991) Diagnostic criteria for facioscapulohumeral muscular dystrophy. Neuromuscul Disord 1: 231-234.

4. Laforet $\mathrm{P}$, de Toma C, Eymard B, Becane HM, Jeanpierre M, et al. (1998)
Cardiac involvement in genetically confirmed facioscapulohumeral muscular dystrophy. Neurology 51: 1454-1456.

5. Kohler J, Rupilius B, Otto M, Bathke K, Koch MC (1996) Germline mosaicsm in 4 q35 facioscapulohumeral muscular dystrophy (FSHD1A) occurring predominately in oogenesis. Hum Genet 98: 485-490.

6. Hassan A, Jones LK Jr, Milone M, Kumar N (2012) Focal and other unusual presentations of facioscapulohumeral muscular dystrophy. Muscle Nerve 46: 421-425.

7. Tawil R, Van Der Maarel SM (2006) Facioscapulohumeral muscular dystrophy. Muscle Nerve 34: 1-15.

8. Lemmers RJLF, Vad Der Maarel SM (1993-1999) Facioscapulohumeral muscular dystrophy. In: Pagon RA, Bird TD, Dolan CR, Stephens K (Eds) Genereviews [Internet]. Seattle, WA: University of Washington.

9. Fitzsimons RB, Gurwin EB, Bird AC (1987) Retinal vascular abnormalities in facioscapulohumeral muscular dystrophy. A general association with genetic and therapeutic implications. Brain 110: 631-648.

10. Shahrizaila N, Wills AJ (2005) Signficance of Beevor's sign in facioscapulohumeral dystrophy and other neuromuscular diseases. J Neurol Neurosurg Psychiatry 76: 869-870.

11. Kan HE, Janssen BH, Voet NBM (2013) Facioscapulohumeral Dystrophy. In: Wattjes MP, Fischer D (Eds). Neuromuscular Imaging. New York: Springer, pp. 95-304

12. Awerbach GI, Nigro MA, Wishnow R (1990) Beevor's sign and facioscapulohumeral dystrophy. Arch Neurol 47: 1208-1209.

13. Padberg GW, Brouwer OF, de Keizer RF, Dijkman G, Wijmenga C, et al (1995) On the significance of retinal vascular disease and hearing loss in facioscapulohumeral muscular dystrophy. Muscle Nerve Suppl S73-S80.

14. Wohlgemuth $M$, van der Kooi EL, van Kesteren RG, van der Maarel SM, Padberg GW (2004) Ventilatory support in facioscapulohumeral muscular dystrophy. Neurology 63: 176-178.

15. (1997) A prospective, quantitative study of the natural history of facioscapulohumeral muscular dystrophy (FSHD): implications for therapeutic trials. The FSH-DY Group. Neurology 48: 36-46.

16. Zatz M, Marie SK, Cerqueira A, Vainzof M, Pavanello RC, et al. (1998) The facioscapulohumeral muscular dystrophy (FSHD1) gene affects males more severely and more frequently than females. Am J Med Genet 77: 155-161.

17. Sacconi S, Salviati L, Bourget I, Figarella D, Pereon Y, et al. (2006) Diagnostic challenges in facioscapulohumeral muscular dystrophy. Neurology 67: 14641466. 